\title{
Silica-coated Nanocomposites of Magnetic Nanoparticles and Quantum Dots
}

\author{
Dong Kee Yi, S. Tamil Selvan, Su Seong Lee, Georgia C. Papaefthymiou, \\ Darshan Kundaliya, and Jackie Y. Ying*
}

\section{Contents:}

Enlarged images of Figure 1 (Figure SI1), p. S-2

Enlarged images of Figure 2 (Figure SI2), p. S-3

EDX data (Figure SI3), p. S-4

XRD patterns (Figure SI4), p. S-5

XPS spectrum (Figure SI5), p. S-6

$\mathrm{N}_{2}$ sorption isotherm (Figure SI6), p. S-7

Normalized magnetization data (Figure SI7), p. S-8

Detailed experimental procedure for the preparation of $\mathrm{SiO}_{2} / \mathrm{MP}-\mathrm{QD}, \mathrm{p}$. S-9 


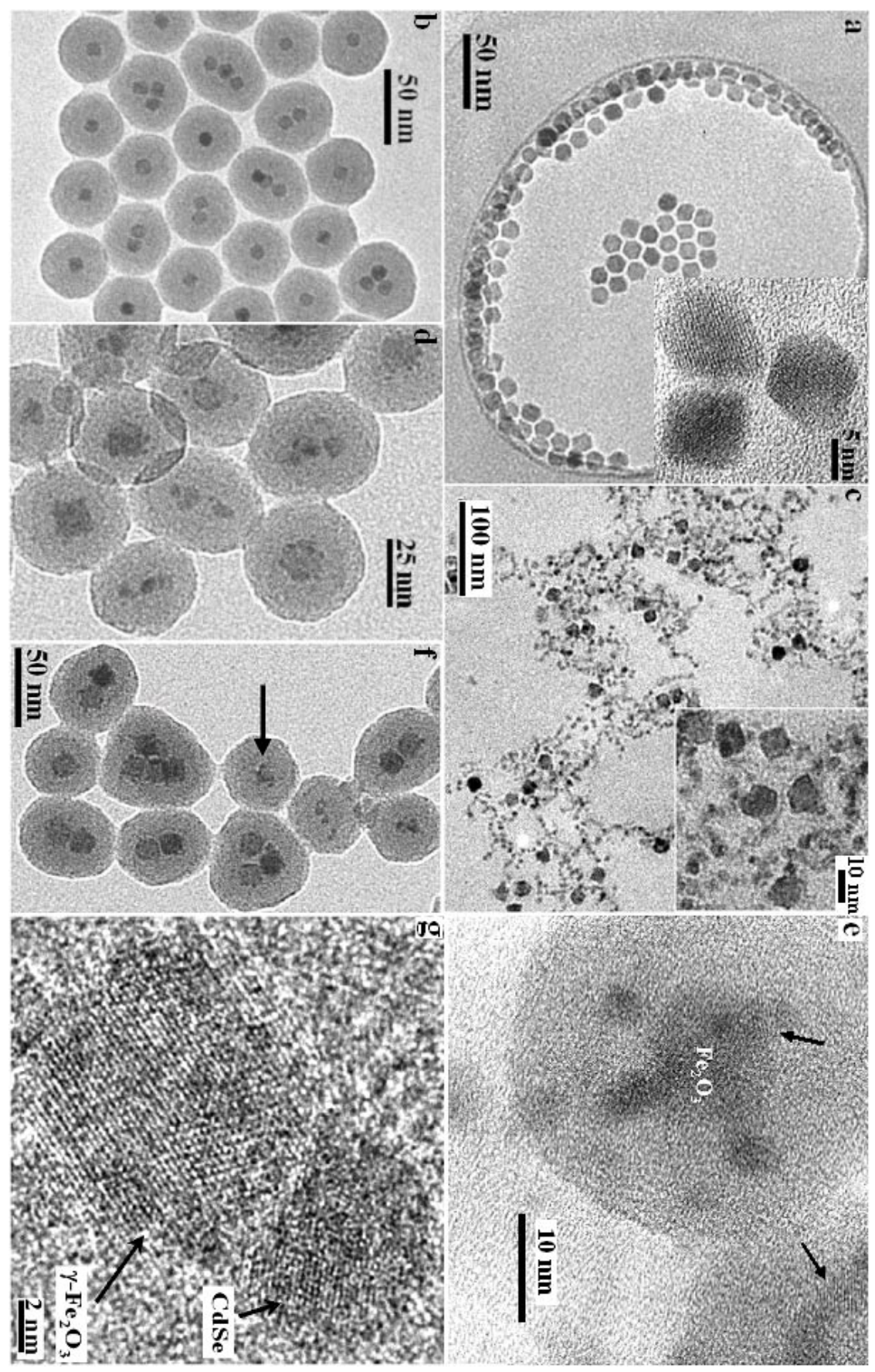

Figure SI1. Enlarged images of Figure 1. 

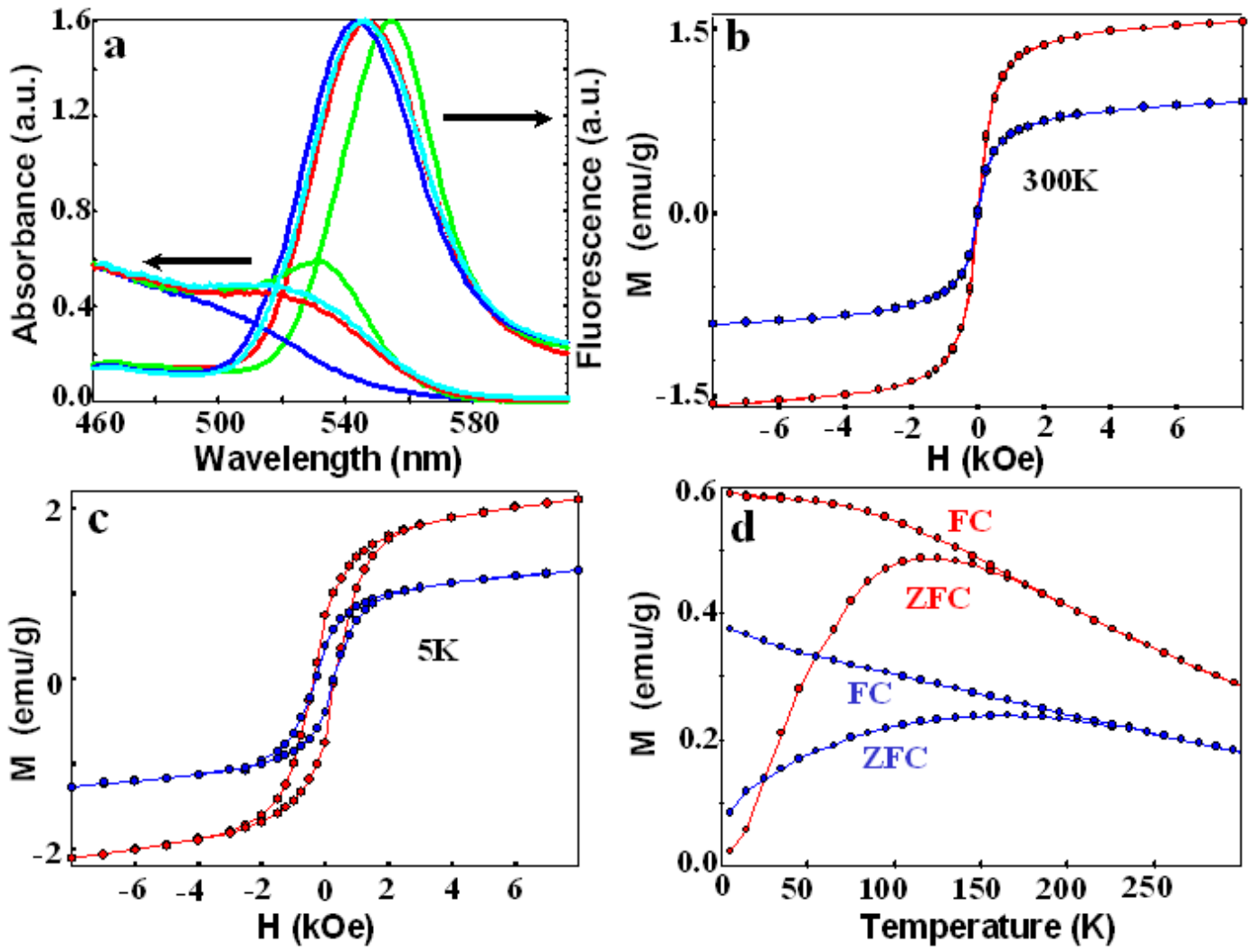

Figure SI2. Enlarged images of Figure 2. 

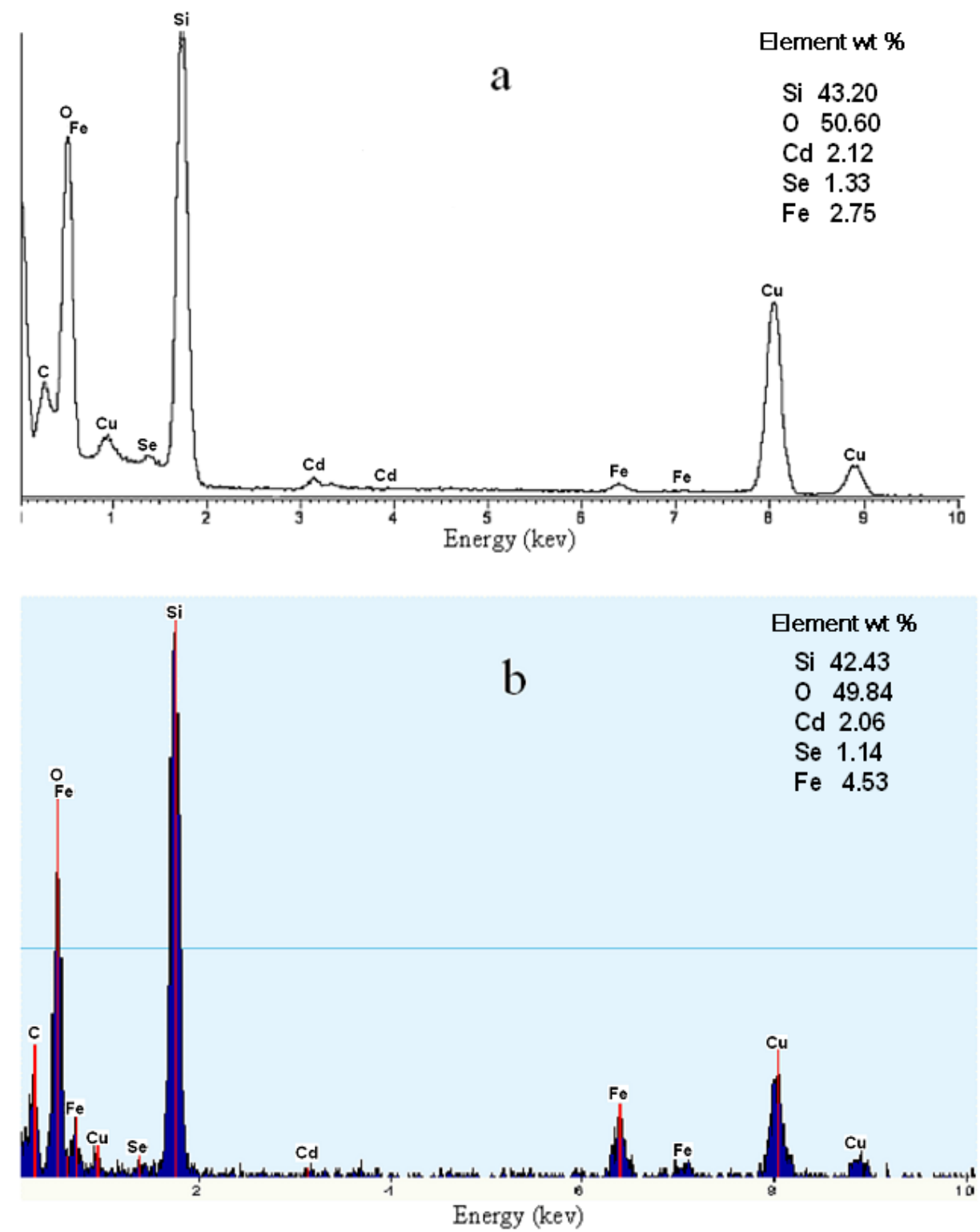

Figure SI3. EDX data of $\mathrm{SiO}_{2} / \mathrm{MP}-\mathrm{QD}$ nanocomposite particles after (a) $8 \mathrm{~h}$ and (b) $48 \mathrm{~h}$ of reaction. 

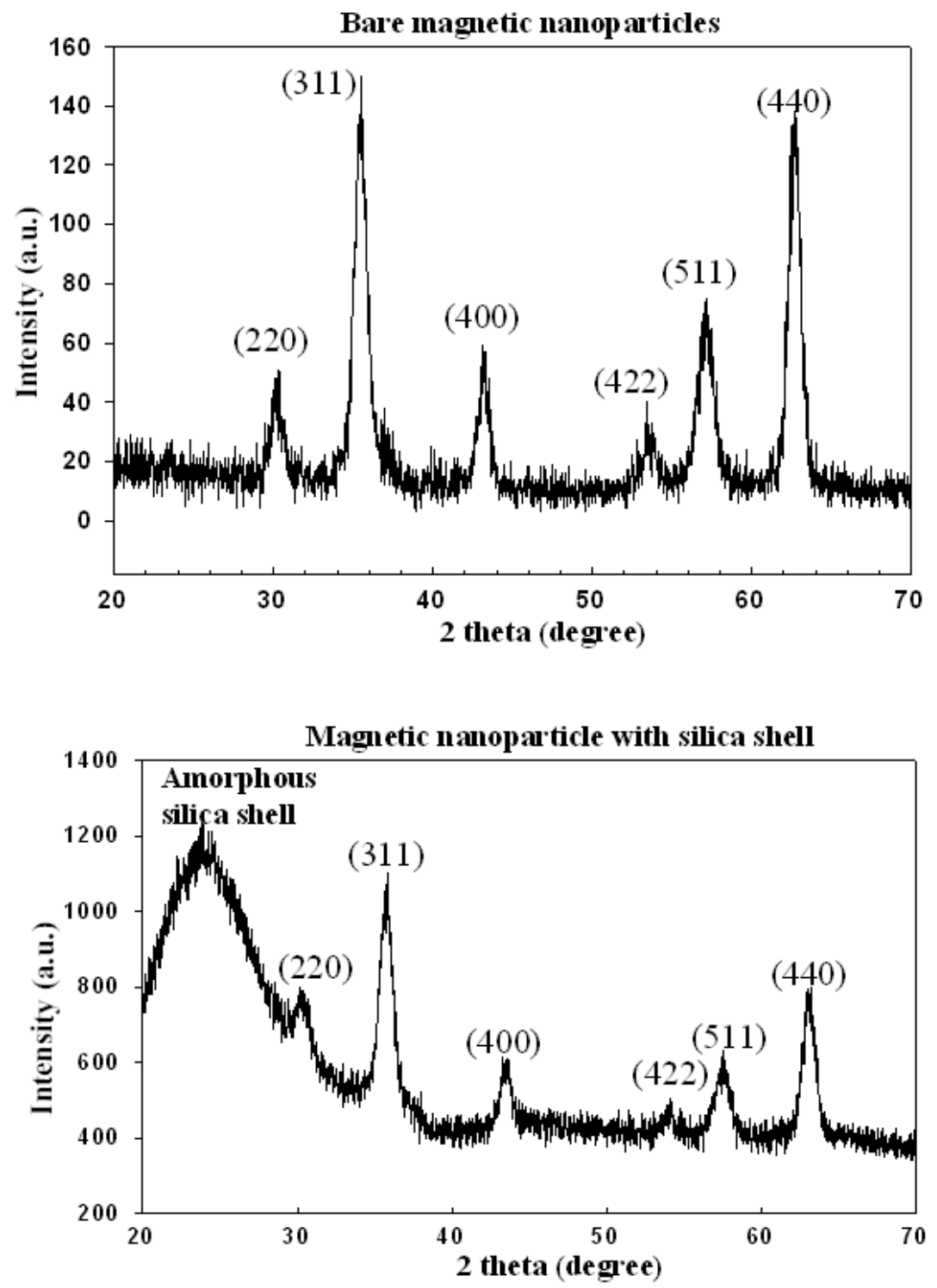

Figure SI4. XRD patterns of bare $\mathrm{MP}$ (top) and $\mathrm{SiO}_{2} / \mathrm{MP}$ nanocomposites (bottom). 


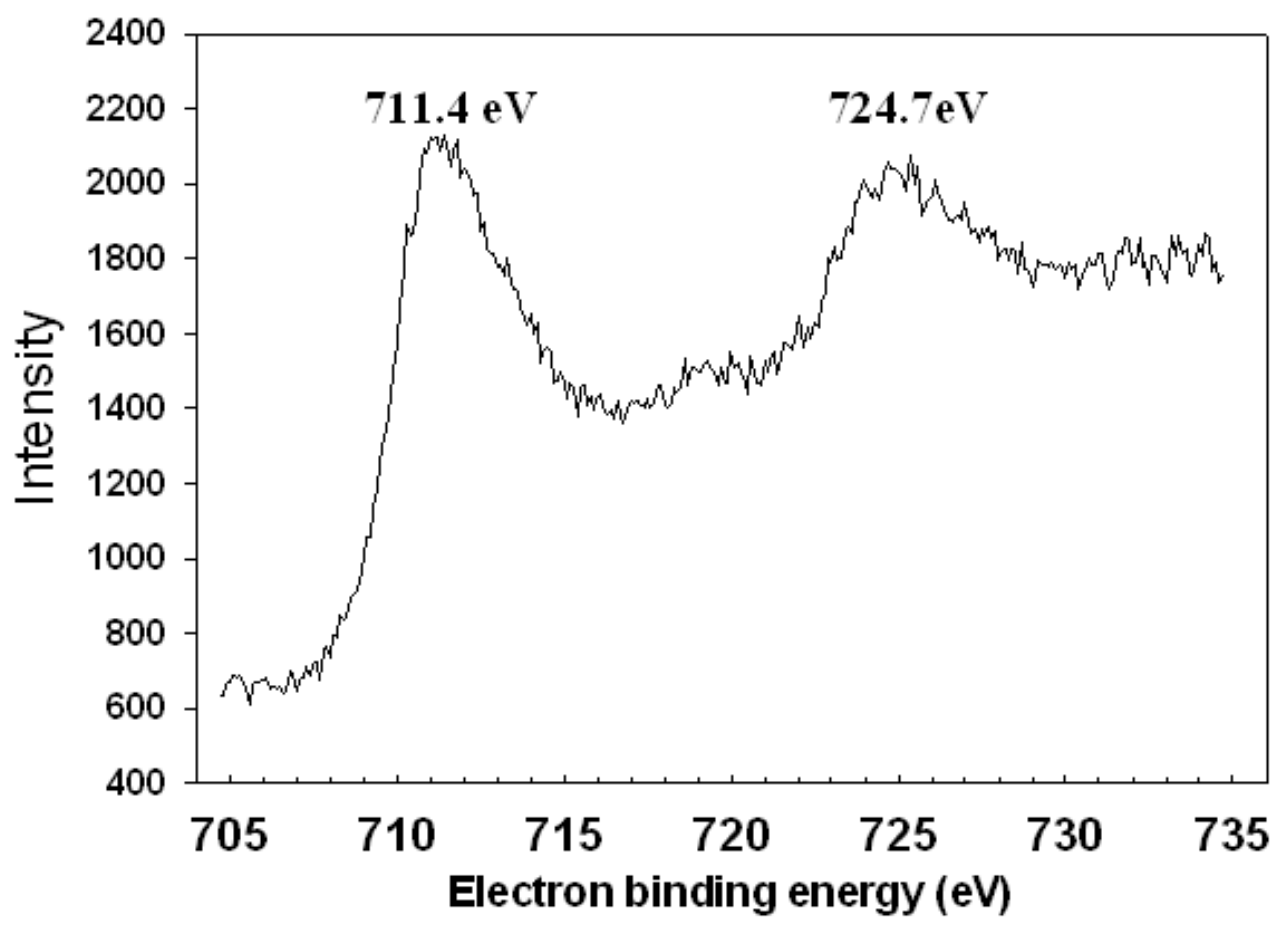

Figure SI5. XPS spectrum for bare MPs. 
BET $\mathrm{N}_{2}$ sorption isotherm

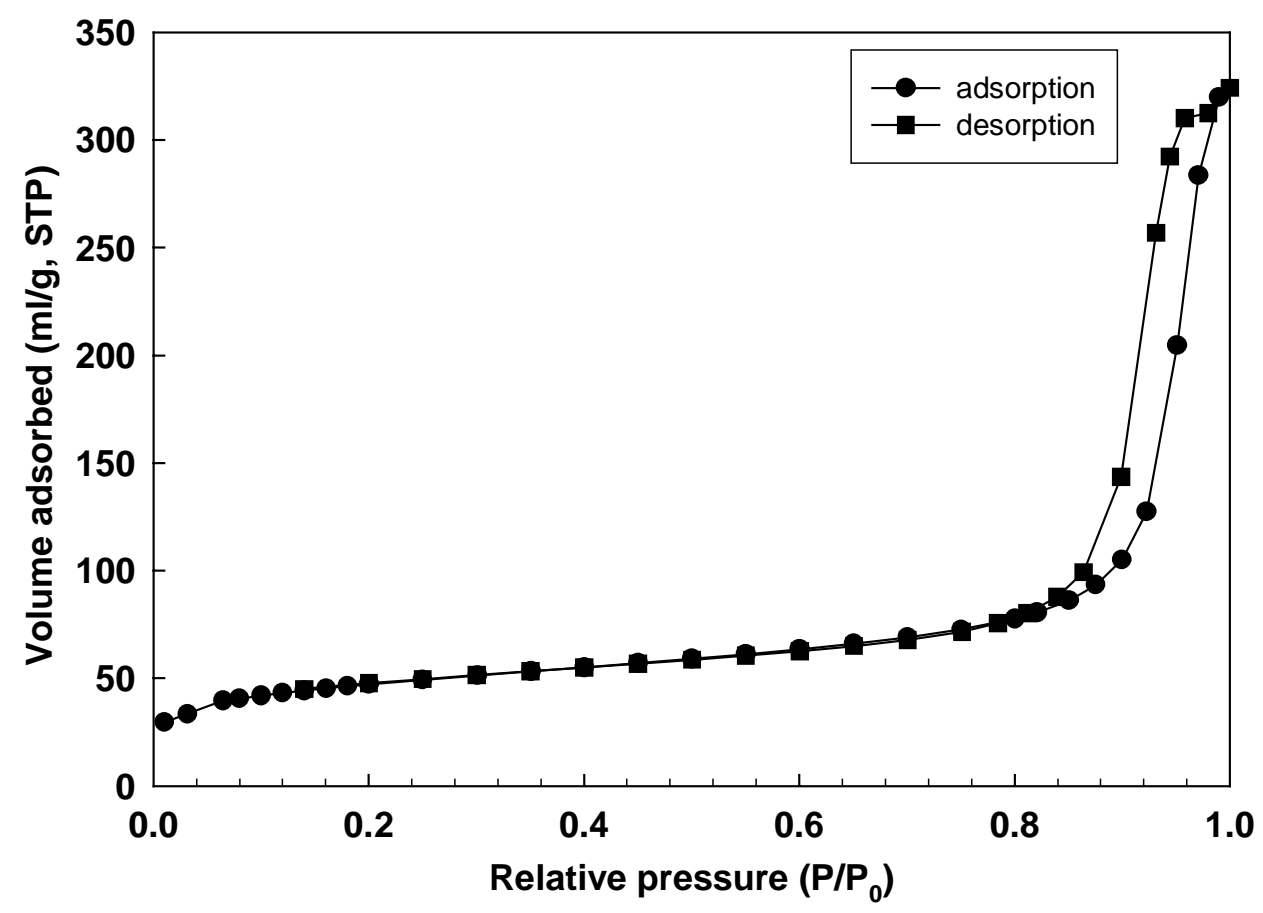

Figure SI6. $\mathrm{N}_{2}$ adsorption-desorption isotherm for $\mathrm{SiO}_{2}$ /MP-QD. 

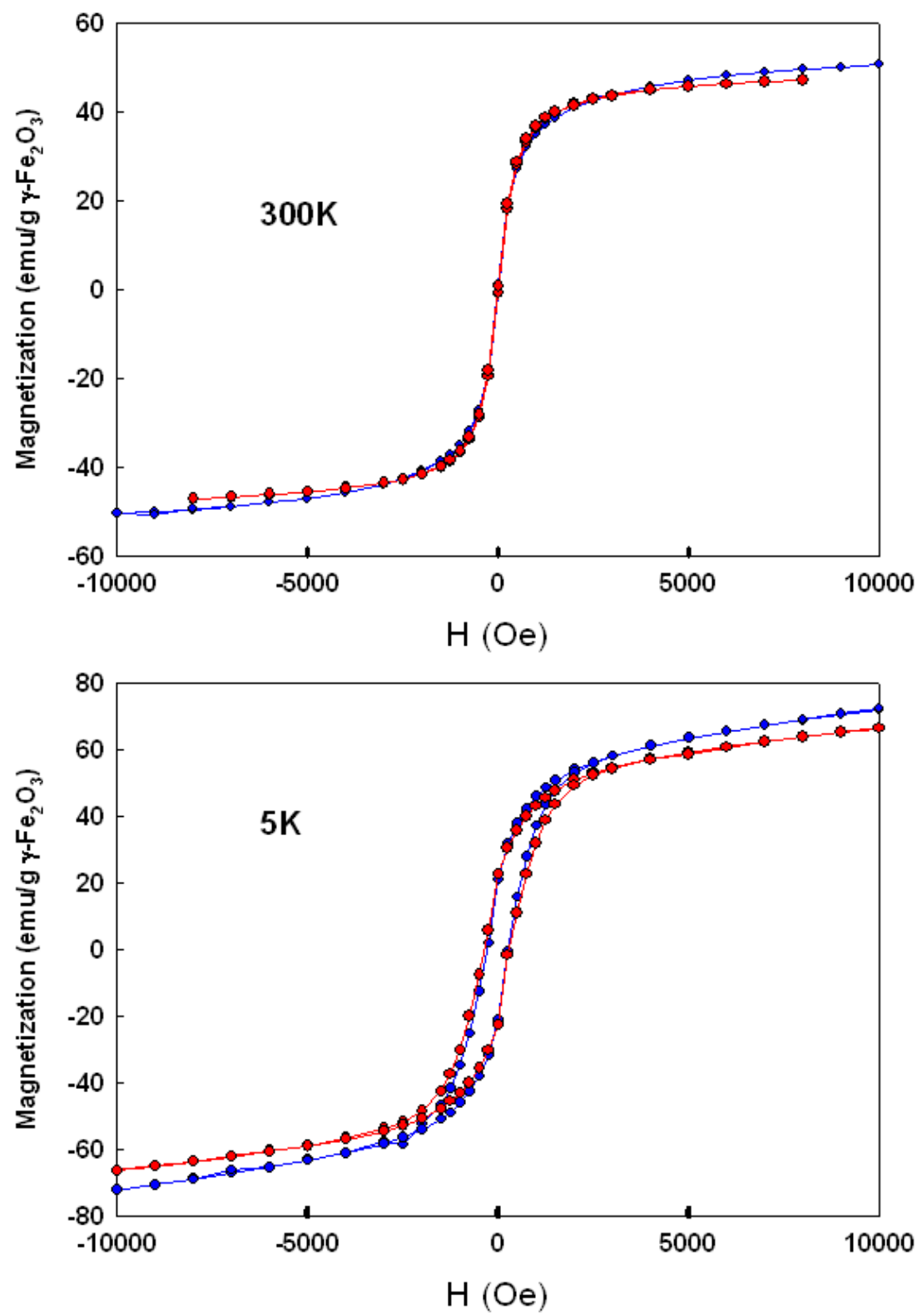

Figure SI7. Magnetization values normalized to the $\gamma-\mathrm{Fe}_{2} \mathrm{O}_{3}$ content for $\mathrm{SiO}_{2} / \mathrm{MP}$ (red) and $\mathrm{SiO}_{2} / \mathrm{MP}-\mathrm{QD}$ (blue) at $300 \mathrm{~K}$ (top) and $5 \mathrm{~K}$ (bottom). 


\section{Detailed Experimental Procedure for the Preparation of $\mathrm{SiO}_{2} / \mathrm{MP}-\mathrm{QD}$}

Polyoxyethylene(5)nonylphenyl ether $(0.23 \mathrm{~g}, 0.544 \mathrm{mmol}$, Igepal CO-520, containing 50 mol\% hydrophilic group, Aldrich) was dispersed in a scintillation tube containing cyclohexane (4.5 ml, ACS grade) by sonication. Next, $400 \mu \mathrm{l}$ of $\gamma-\mathrm{Fe}_{2} \mathrm{O}_{3}$ nanoparicles dispersed in cyclohexane $(0.5 \mathrm{mg} / \mathrm{ml})$ and $160 \mu \mathrm{l}$ of CdSe QDs dispersed in cyclohexane (1 $\mathrm{mg} / \mathrm{ml}$ ) were added to the scintillation tube. The resulting mixture was vortexed until the mixture became transparent. Ammonium hydroxide $(29.4 \%, 40 \mu \mathrm{l})$ was then added to form a transparent, brown reverse microemulsion. Lastly, tetraethylorthosilicate $(30 \mu \mathrm{l}$, TEOS, Aldrich) was added, and gently vortexed. The reaction was continued for $\leq 48 \mathrm{~h}$ at room temperature. The resulting $\mathrm{SiO}_{2} / \mathrm{MP}-\mathrm{QD}$ nanocomposite particles were precipitated by adding methanol, and collected by centrifuging at $7500 \mathrm{rpm}$. The collected $\mathrm{SiO}_{2} / \mathrm{MP}-\mathrm{QD}$ nanoparticles were redispersed in ethanol, and purified by sonication and centrifugation. The centrifugation and ethanol washes were repeated four times. The nanoparticles could also be magnetically collected. The final product was redispersed in ethanol or deionized water. The ethanol-dispersed $\mathrm{SiO}_{2}$ /MP-QD nanoparticles were used for UV-VIS/fluorometer and TEM analyses. For SQUID and nitrogen sorption analyses, ethanol-dispersed $\mathrm{SiO}_{2} / \mathrm{MP}-\mathrm{QD}$ nanoparticles were first centrifuged and dried in oven for $24 \mathrm{~h}$ at $70^{\circ} \mathrm{C}$. 